\title{
Usefulness of using additional ultrasonic dissection device in breast cancer surgery: a retrospective cohort study
}

\author{
Kyoung-Eun Kim ${ }^{1,2} \wedge$, Heeseung Park ${ }^{1,2} \wedge$, Seong Hwan Bae ${ }^{3 \wedge}$, Boo-Young Hwang ${ }^{4}$, Taewoo Kang ${ }^{1,2} \wedge$ \\ ${ }^{1}$ Busan Cancer Center, Pusan National University Hospital, Busan, Republic of Korea; ${ }^{2}$ Biomedical Research Institute, Pusan National University \\ Hospital, Busan, Republic of Korea; ${ }^{3}$ Department of Plastic and Reconstructive Surgery, Pusan National University Hospital, Busan, Republic of \\ Korea; ${ }^{4}$ Department of Anesthesia and Pain Medicine, Pusan National University School of Medicine, Busan, Republic of Korea \\ Contributions: (I) Conception and design: KE Kim, H Park, T Kang; (II) Administrative support: T Kang; (III) Provision of study materials or \\ patients: T Kang, SH Bae, BY Hwang; (IV) Collection and assembly of data: KE Kim; (V) Data analysis and interpretation: KE Kim, H Park, T \\ Kang; (VI) Manuscript writing: All authors; (VII) Final approval of manuscript: All authors. \\ Correspondence to: Prof. Taewoo Kang. Busan Cancer Center, Pusan National University Hospital, 179 Gudeok-ro, Seo-gu, Busan, Republic of Korea. \\ Email: taewoo.d.kang@gmail.com.
}

\begin{abstract}
Background In breast cancer surgery, electrocautery (EC) is commonly used with the basic method of knot tying, and there are few reports of using other devices such as ultrasonic dissection device (UDD). This study was designed to compare the case of using EC with the basic method of knot tying and the case of using UDD in breast cancer surgery.

Methods: From April 2019 to March 2020, 376 patients who underwent breast cancer surgery at Pusan National University Hospital were enrolled. We compared operation time, complications, and blood loss volume between surgery with and without UDD.

Results: We included 306 patients for the final analysis, 142 in the control group and 164 in the trial group. The operation time [minutes (min)] was significantly reduced in the trial group compared to the control group (111.2 vs. $95.5 \mathrm{~min}, \mathrm{P}<0.001)$. In subgroup analysis, the operation time in the trial group was significantly reduced. There was no significant difference in intraoperative blood loss $(\mathrm{P}=0.999)$ and complications [seroma $(\mathrm{P}=0.965)$, hematoma $(\mathrm{P}=0.999)$, cellulitis $(\mathrm{P}=0.999)]$.
\end{abstract}

Conclusions: Our study showed that the use of a UDD for surgeons to select instruments for breast cancer surgery may be a good option for both patients and surgeons.

Keywords: Breast neoplasm; ultrasonic device; electrocautery (EC)

Submitted Sep 14, 2021. Accepted for publication Nov 19, 2021.

doi: $10.21037 / g s-21-643$

View this article at: https://dx.doi.org/10.21037/gs-21-643

\section{Introduction}

Recently, breast cancer surgery is changing to reduce the extent of surgical resection. First, neoadjuvant chemotherapy is used to reduce breast cancer lesions to reduce the size of tumors that need to be surgically resected
$(1,2)$. In addition, when axillary lymph node metastasis was confirmed, axillary lymph node dissection (AD) had to be performed, but based on recent studies, it is possible to do without $\mathrm{AD}$ when the tumor size is smaller than $5 \mathrm{~cm}$, or when there are less than 2 metastatic lymph nodes in sentinel lymph node biopsy (SN) (3).

\footnotetext{
^ ORCID: Kyoung-Eun Kim, 0000-0001-6487-0935; Heeseung Park, 0000-0001-9889-5217; Seong Hwan Bae, 0000-0002-7203-8978; Boo-Young Hwang, 0000-0001-6098-0627; Taewoo Kang, 0000-0002-6279-0904.
} 
However, surgical resection is still needed for breast cancer. There are a number of instruments that make the operation more convenient. Typical commonly used ones are monopolar or bipolar electrocautery (EC), and ultrasonic dissection device (UDD, Harmonic Focus ${ }^{\circledR}+$ Shears, Curved tip, Ethicon US, Cincinnati, OH, USA), and Ligasure, etc. The UDD and Ligasure are devices that can make hemostasis more complete without complications, and safer and more comfortable to use, compared to EC that have been traditionally used $(4,5)$. Among other surgeries, UDD is widely used in laparoscopic surgery and also widely used in thyroid surgery. In particular, with regard to thyroid surgery, there are many research results related to UDD in thyroid surgery. Several studies have shown that using a UDD can safely dissect, coagulate and simultaneously cut tissue, thus reducing the operation time $(6,7)$.

However, in breast cancer surgery, EC is commonly used with the basic method of knot tying, and there are few reports of using other devices such as UDD. And many of the results of studies comparing EC and UDD have conflicting conclusions (8-12).

We thought that using UDD would enable more detailed hemostasis and tissue ligation than knot tying. And we hypothesized that using UDD would reduce seroma formation, hospital stay, and operation time especially in case of $\mathrm{AD}$. And this study was designed to compare the case of using EC with the basic method of knot tying and the case of using UDD in breast cancer surgery.

We present the following article in accordance with the STROBE reporting checklist (available at https://dx.doi. org/10.21037/gs-21-643).

\section{Methods}

\section{Patients}

From April 2019 to March 2020, 376 patients who underwent breast cancer surgery at Pusan National University Hospital were enrolled.

We retrospectively reviewed the patients' medical records.

One breast surgeon and one plastic surgeon performed the surgery in the same environment. No other hemostatic agent was used such as fibrin sealant. Closed suction drains were used for all patients after hemostasis.

Since we started using UDD for all breast cancer surgeries in October 2019, we decided to compare the groups by dividing them based on October 2019. From
April 2019 to September 2019, patients underwent surgery with an EC with the basic method of knot tying (control group), and from October 2019 to March 2020, an UDD was used together with EC (trial group).

Patients who had breast surgery without axillary surgery, bilateral breast surgery and only axillary surgery without breast surgery were excluded.

The study was conducted in accordance with the Declaration of Helsinki (as revised in 2013). The study was approved by Institutional Ethics Board of Pusan National University Hospital (IRB No. 2006-027-092) and individual consent for this retrospective analysis was waived.

\section{Variables}

Breast operation types were breast-conserving surgery (BCS), mastectomy, nipple-sparing mastectomy (NSM) or skin-sparing mastectomy (SSM) with reconstruction. And axillary operation types were $\mathrm{AD}$ and axillary $\mathrm{SN}$.

For the present study, the following variables were used: (I) operation time [minutes (min)]; the operation time excluded the time related to anesthesia; (II) the last day of less than $30 \mathrm{~mL}$ of drainage for 2 consecutive days amount (days) $(13,14)$; (III) body mass index (BMI, $\left.\mathrm{kg} / \mathrm{m}^{2}\right)$; (IV) weight of specimen [gram (g)]; (V) comorbidity; hypertension, diabetes, cardiovascular disease, pulmonary disease (comorbidities were checked for the presence or absence, and if any of the above-mentioned contents were applicable, it was confirmed as yes); (VI) complications (complications were identified within 1 month after surgery); seroma (it was defined that in case the aspiration was performed within a month after the operation), hematoma, cellulitis; (VII) intraoperative blood loss (mL); the intraoperative blood loss amount was confirmed as high or low based on $50 \mathrm{~mL}$.

What we expected as the primary outcomes were a reduction in operation time and hospital stay (patients were discharged on the last day of less than $30 \mathrm{~mL}$ of drainage for 2 consecutive days amount. Therefore, it could be said that if this period (days) is shortened, the hospital stay period is shortened). Secondary outcome was reduction in complications and intraoperative blood loss.

\section{Statistical analysis}

Statistical analysis was performed with the use of $\mathrm{R}$ 3.5.0 version (R Core Team 2013) statistical software. P values $<0.05$ were considered statistically significant. 


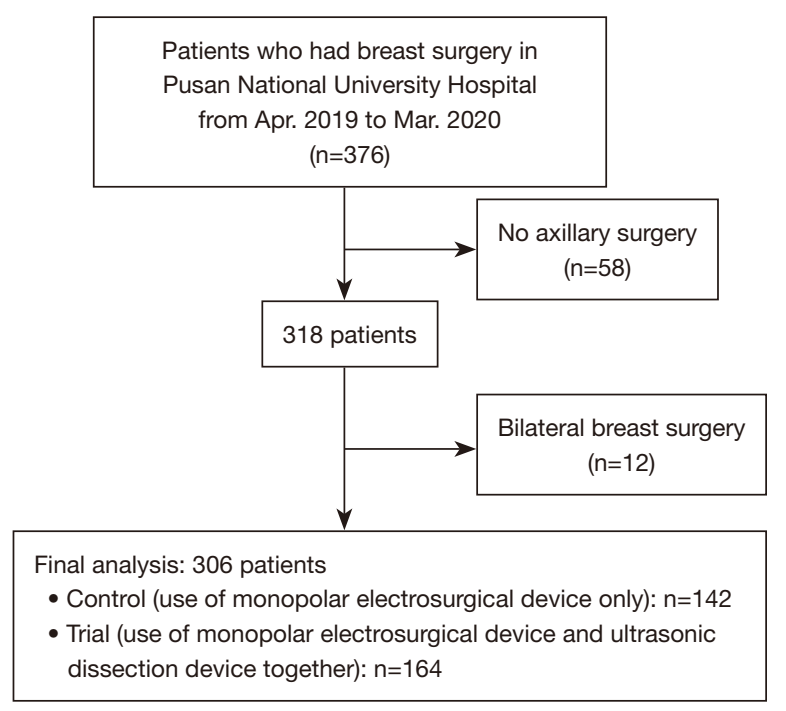

Figure 1 Design and flow of participants through the study.

\section{Results}

We identified a total 376 patients who underwent breast surgery between Apr 2019 and Mar 2020. After excluding cases of no axillary surgery $(\mathrm{n}=58)$ and bilateral breast surgery $(\mathrm{n}=12)$, we included 306 patients for the final analysis (Figure 1).

Patients were classified into "use of EC only (control group, $\mathrm{n}=142$ )" and "use of EC and UDD together (trial group, $\mathrm{n}=164)$ ".

The demographic information of the studied patients is listed in Table 1. There were 155 patients who had BCS, 78 for mastectomy, and 73 for NSM or SSM with reconstruction. Sixty patients had AD and 246 patients had $\mathrm{SN}$. The groups were homogenous with breast operation type, axillary operation type, stage, comorbidity, weight of specimen, and BMI.

It had been shown that operation time might be significantly reduced in the trial group compared to the control group (Table 2). The operation time was $111.2 \mathrm{~min}$ for the control group and $95.5 \mathrm{~min}$ for the trial group in all patients $(\mathrm{P}<0.001)$. And there was significantly reduced operation time in the trial group compared to the control in BCS (92.6 vs. $84.8 \mathrm{~min}, \mathrm{P}=0.003)$, mastectomy (131.8 vs. 109.7 min, $\mathrm{P}=0.006), \mathrm{AD}$ (148.4 vs. $127.5 \mathrm{~min}, \mathrm{P}=0.037$ ), and $\mathrm{SN}$ (100.3 vs. $89.0 \mathrm{~min}, \mathrm{P}=0.003)$.

There was no significant difference in intraoperative blood loss (Table 3) and complications (Table 4).

And there was no significant difference in the last day of less than $30 \mathrm{~mL}$ of drainage for 2 consecutive days amount
(Table 5). The last day of less than $30 \mathrm{~mL}$ of drainage for 2 consecutive days amount was 6.2 days for the control and 6.0 days for the trial in all patients $(\mathrm{P}=0.642)$.

\section{Discussion}

The use of UDD is already widely used as a safe and convenient surgical instrument. However, there are still not many studies on the benefits of using UDD in breast cancer surgery. Also, most of them are the results of mastectomy or reconstruction or axillary dissection (9,15-17).

Deo et al. compared the group using the UDD and the group using EC in the case of modified radical mastectomy, there was no difference in operation time, and the amount of drainage and bleeding was significantly lower in the group using the UDD (15). However, in Yilmaz et al., this study was conducted on mastectomy, and there was no difference in the amount of drain according to the use of the scalpel, EC, and UDD. The operation time and blood loss significantly decreased when using the UDD (18). In the two studies, there is a slight difference in the variables of the group being compared, but in a larger view, it is a study that confirms the difference depending on whether or not UDD is used, and it can be confirmed that the results are different.

The seroma formation is known to be related to the type of surgery, breast size, number of involved lymph nodes, tumor size and age (19-21). EC uses direct thermal energy than can diffuse into deeper tissues and high thermal energy leaves huge number of devitalized tissues. Therefore, there are many research results showing that using UDD reduces seroma formation than using EC (22). However, there was no difference in seroma formation in our study. The reason for the above result is that most of the lymphatic vessels were knotted even when only EC was used, so it is thought that there was no difference in seroma formation compared to the case that UDD was additionally used.

The importance of our study is that it can be used to compare whether there is a difference in using the UDD according to each operation type such as BCS, AD, and SN, as well as the case of mastectomy.

This study showed that the operation time was significantly reduced when the UDD was used. The operation time was reduced in the trial group, and it is most important to reduce the operation time in the $\mathrm{AD}$ group. Complications such as seroma and hematomas can occur in $\mathrm{AD}$, and it is particularly important to minimize damage to blood vessels and nerve structures during surgery (Figure 2). 
Table 1 Patient characteristics

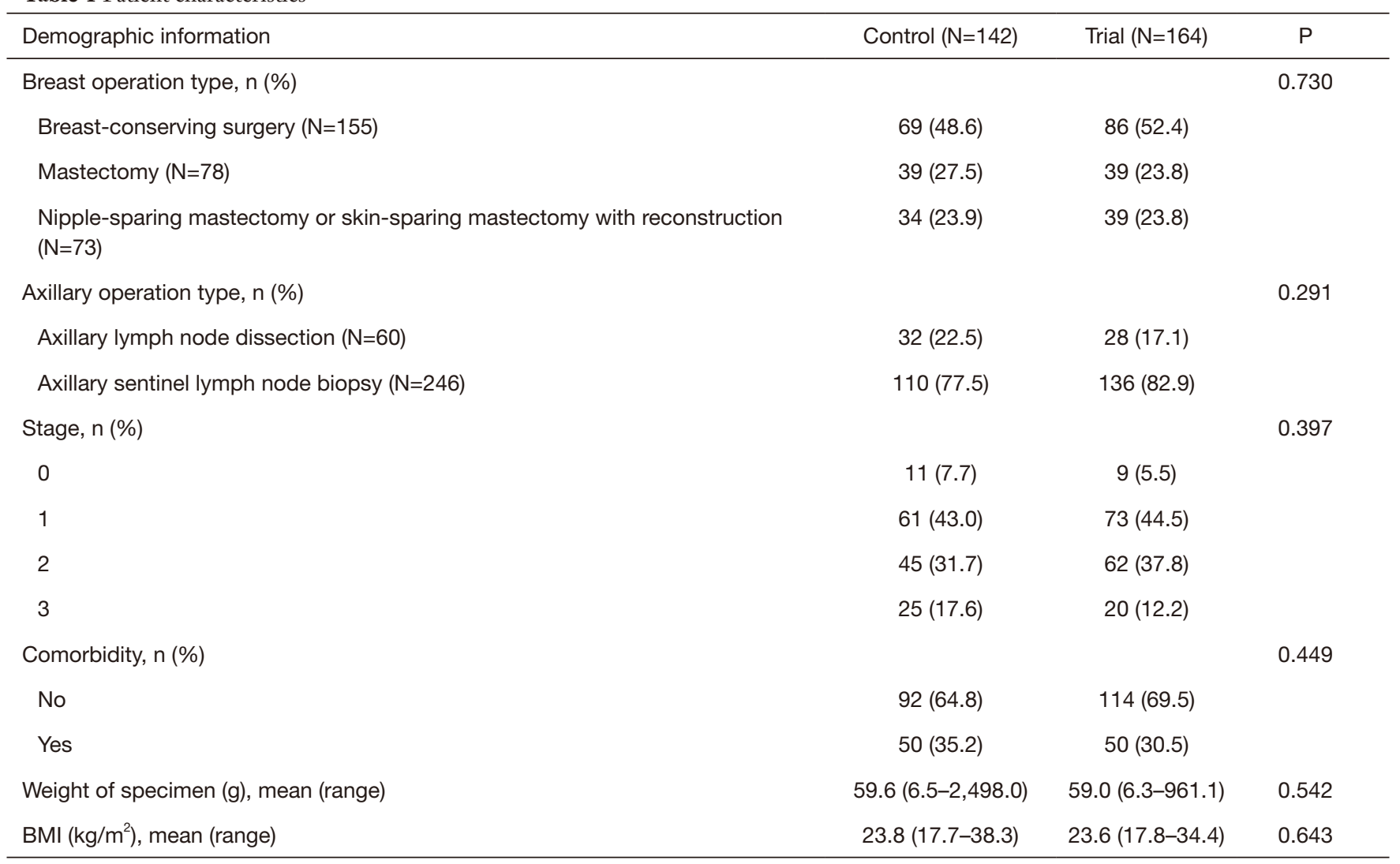

$\mathrm{BMI}$, body mass index.

Table 2 Operation time (min)

\begin{tabular}{|c|c|c|c|}
\hline Operation type & Control & Trial & $\mathrm{P}$ \\
\hline Breast-conserving surgery (range) & $92.6(65.0-135.0)(\mathrm{N}=69)$ & $84.8(60.0-145.0)(\mathrm{N}=86)$ & 0.003 \\
\hline Mastectomy (range) & $131.8(75.0-290.0)(\mathrm{N}=39)$ & $109.7(70.0-215.0)(\mathrm{N}=39)$ & 0.006 \\
\hline $\begin{array}{l}\text { Nipple-sparing mastectomy or Skin-sparing mastectomy } \\
\text { with reconstruction (range) }\end{array}$ & $125.1(65.0-280.0)(\mathrm{N}=34)$ & $105.1(55.0-260.0)(\mathrm{N}=39)$ & 0.098 \\
\hline Axillary sentinel lymph node biopsy $(\mathrm{SN})^{\dagger}$ (range) & $100.3(65.0-280.0)(\mathrm{N}=110)$ & $89.0(55.0-260.0)(\mathrm{N}=136)$ & 0.003 \\
\hline
\end{tabular}

\footnotetext{
${ }^{\dagger}$, axillary surgery was not performed alone, it was always performed with breast surgery.
}

Therefore, that the operation time can be shortened even though there is no difference in the frequency of complications can be an important part in the selection of surgical instruments.

The reason why the operation time could be reduced is thought to be that the need for the operator to perform actions such as tie, which should be performed directly when hemostasis, is eliminated as the UDD is used. Moreover, surgeon could more concentrate on the consecutive surgery because it could reduce the physical burden.

Reducing the need for these techniques may also play an important role in reducing operator fatigue during surgery. 
Table 3 Intraoperative blood loss $(\mathrm{mL})$

\begin{tabular}{lccc}
\hline Intraoperative blood loss & Control $(\mathrm{N}=142), \mathrm{n}(\%)$ & Trial (N=164), $\mathrm{n}(\%)$ & $\mathrm{P}$ \\
\hline$\leq 50 \mathrm{~mL}$ & $142(100.0)$ & $163(99.4)$ & 0.999 \\
$>50 \mathrm{~mL}$ & $0(0.0)$ & $1(0.6)$ & \\
\hline
\end{tabular}

Table 4 Complications

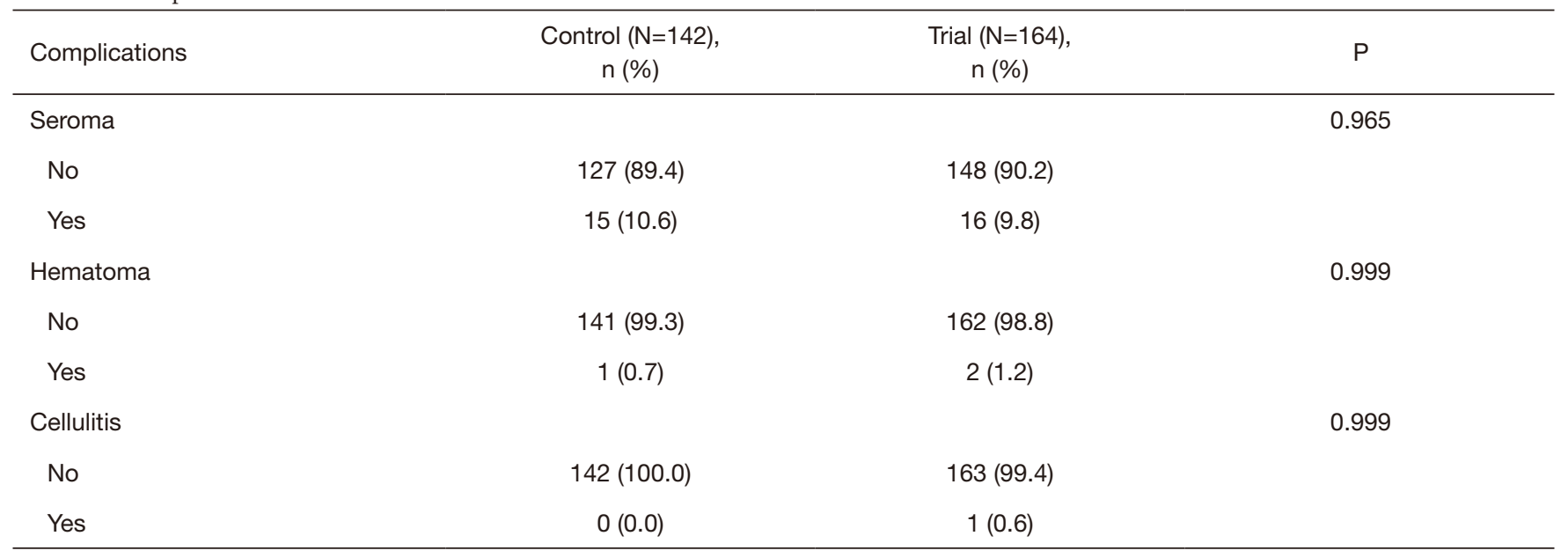

Table 5 The last day of less than $30 \mathrm{~mL}$ of drainage for 2 consecutive days amount (days)

\begin{tabular}{|c|c|c|c|}
\hline Operation type & Control & Trial & $\mathrm{P}$ \\
\hline Mastectomy (range) & $7.7(2.0-22.0)(\mathrm{N}=39)$ & $6.7(2.0-29.0)(\mathrm{N}=39)$ & 0.355 \\
\hline $\begin{array}{l}\text { Nipple-sparing mastectomy or Skin-sparing mastectomy } \\
\text { with reconstruction (range) }\end{array}$ & $10.5(4.0-21.0)(\mathrm{N}=34)$ & $11.1(4.0-29.0)(\mathrm{N}=39)$ & 0.609 \\
\hline Axillary lymph node dissection (range) & $9.9(3.0-22.0)(\mathrm{N}=32)$ & $11.2(4.0-29.0)(\mathrm{N}=28)$ & 0.451 \\
\hline Axillary sentinel lymph node biopsy (range) & $5.2(1.0-20.0)(\mathrm{N}=110)$ & $4.9(1.0-18.0)(\mathrm{N}=136)$ & 0.565 \\
\hline
\end{tabular}

Furthermore, the reduction in the operation time means that the anesthesia time is shortened, which may help reduce problems such as complications after surgery (23).

The reason there was no significant difference in the amount of drain is thought to be that the amount of drainage was sufficiently well controlled even UDD was not used.

But our study has several limitations. First, it is the cost incurred by using the UDD. This can be an additional cost for surgery, which can be a financial burden for patients. The additional cost to the patient in Korea is about $\$ 450$. However, in Korea, patients pay about $\$ 1,800$ for breast cancer surgery. Therefore, the cost of using UDD is unlikely to be a burden to the patient. The second is that the design of this study is a retrospective study and the third is a single center study. However, because the patient background did not differ significantly between the two groups, the difference in outcome is considered to be observing the difference in the effectiveness of the instruments. Third, since it is a retrospective study, the study is conducted based on medical records. Therefore, it is difficult to make accurate measurements and compare them. In our hospital, when the amount of intraoperative bleeding is so small that it cannot be measured, it is marked on the surgical record as less than $50 \mathrm{~mL}$. In this study, the 


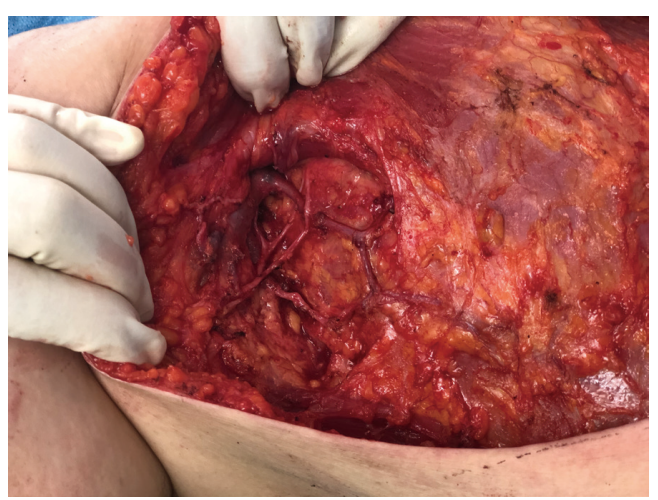

Figure 2 Axillary lymph node dissection (AD) was performed using an ultrasonic dissection device (UDD), and hemostasis was achieved after surgery without damage to major structures.

amount of intraoperative bleeding was analyzed with less than $50 \mathrm{~mL}$ rather than an accurate measurement value.

\section{Conclusions}

The UDD use group showed decreased operation time. Therefore, our study showed that the use of a UDD for surgeons to select instruments for breast cancer surgery may be a good option for both patients and surgeons.

\section{Acknowledgments}

Funding: None.

\section{Footnote}

Reporting Checklist: The authors have completed the STROBE reporting checklist. Available at https://dx.doi. org/10.21037/gs-21-643

Data Sharing Statement: Available at https://dx.doi. org/10.21037/gs-21-643

Peer Review File: Available at https://dx.doi.org/10.21037/ gs-21-643

Conflicts of Interest: All authors have completed the ICMJE uniform disclosure form (available at https://dx.doi. org/10.21037/gs-21-643). The authors have no conflicts of interest to declare.

Ethical Statement: The authors are accountable for all aspects of the work in ensuring that questions related to the accuracy or integrity of any part of the work are appropriately investigated and resolved. The study was conducted in accordance with the Declaration of Helsinki (as revised in 2013). The study was approved by Institutional Ethics Board of Pusan National University Hospital (IRB No. 2006-027-092) and individual consent for this retrospective analysis was waived.

Open Access Statement: This is an Open Access article distributed in accordance with the Creative Commons Attribution-NonCommercial-NoDerivs 4.0 International License (CC BY-NC-ND 4.0), which permits the noncommercial replication and distribution of the article with the strict proviso that no changes or edits are made and the original work is properly cited (including links to both the formal publication through the relevant DOI and the license). See: https://creativecommons.org/licenses/by-nc-nd/4.0/.

\section{References}

1. Mathew J, Asgeirsson KS, Agrawal A, et al. Neoadjuvant chemotherapy in locally advanced primary breast cancers: the Nottingham experience. Eur J Surg Oncol 2007;33:972-6.

2. Gralow JR, Burstein HJ, Wood W, et al. Preoperative therapy in invasive breast cancer: pathologic assessment and systemic therapy issues in operable disease. J Clin Oncol 2008;26:814-9.

3. Boland MR, Prichard RS, Daskalova I, et al. Axillary nodal burden in primary breast cancer patients with positive pre-operative ultrasound guided fine needle aspiration cytology: management in the era of ACOSOG Z011. Eur J Surg Oncol 2015;41:559-65.

4. Diamantis T, Kontos M, Arvelakis A, et al. Comparison of monopolar electrocoagulation, bipolar electrocoagulation, Ultracision, and Ligasure. Surg Today 2006;36:908-13.

5. Seehofer D, Mogl M, Boas-Knoop S, et al. Safety and efficacy of new integrated bipolar and ultrasonic scissors compared to conventional laparoscopic 5-mm sealing and cutting instruments. Surg Endosc 2012;26:2541-9.

6. Cirocchi R, D'Ajello F, Trastulli S, et al. Meta-analysis of thyroidectomy with ultrasonic dissector versus conventional clamp and tie. World J Surg Oncol 2010;8:112.

7. Revelli L, Damiani G, Bianchi CB, et al. Complications in thyroid surgery. Harmonic Scalpel, Harmonic Focus versus Conventional Hemostasis: A meta-analysis. Int J 
Surg 2016;28 Suppl 1:S22-32.

8. Porter KA, O'Connor S, Rimm E, et al. Electrocautery as a factor in seroma formation following mastectomy. Am J Surg 1998;176:8-11.

9. Nadkarni MS, Rangole AK, Sharma RK, et al. Influence of surgical technique on axillary seroma formation: a randomized study. ANZ J Surg 2007;77:385-9.

10. Cheng H, Clymer JW, Ferko NC, et al. A systematic review and meta-analysis of Harmonic technology compared with conventional techniques in mastectomy and breast-conserving surgery with lymphadenectomy for breast cancer. Breast Cancer (Dove Med Press) 2016;8:125-40.

11. Huang J, Yu Y, Wei C, et al. Harmonic Scalpel versus Electrocautery Dissection in Modified Radical Mastectomy for Breast Cancer: A Meta-Analysis. PLoS One 2015;10:e0142271.

12. Currie A, Chong K, Davies GL, et al. Ultrasonic dissection versus electrocautery in mastectomy for breast cancer - a meta-analysis. Eur J Surg Oncol 2012;38:897-901.

13. Ko E, Han W, Cho J, et al. Fibrin glue reduces the duration of lymphatic drainage after lumpectomy and level II or III axillary lymph node dissection for breast cancer: a prospective randomized trial. J Korean Med Sci 2009;24:92-6.

14. Staradub VL, Morrow M. Modified radical mastectomy with knife technique. Arch Surg 2002;137:105-10.

15. Deo SV, Shukla NK, Asthana S, et al. A comparative study of modified radical mastectomy using harmonic scalpel and electrocautery. Singapore Med J 2002;43:226-8.

16. Mittal P, Kumar A, Kaur S, et al. A Comparative Study of the Use of Harmonic Scalpel versus Unipolar Cautery in Modified Radical Mastectomy. Niger J Surg 2017;23:20-5.

17. Michalik T, Matkowski R, Biecek P, et al. The use of ultrasonic scalpel lowers the risk of post-mastectomy seroma formation in obese women. J Cancer 2019;10:3481-5.

18. Yilmaz KB, Dogan L, Nalbant H, et al. Comparing scalpel, electrocautery and ultrasonic dissector effects: the impact on wound complications and pro-inflammatory cytokine levels in wound fluid from mastectomy patients. J Breast Cancer 2011;14:58-63.

19. Hashemi E, Kaviani A, Najafi M, et al. Seroma formation after surgery for breast cancer. World J Surg Oncol 2004;2:44.

20. Kuroi K, Shimozuma K, Taguchi T, et al. Pathophysiology of seroma in breast cancer. Breast Cancer 2005;12:288-93.

21. Agrawal A, Ayantunde AA, Cheung KL. Concepts of seroma formation and prevention in breast cancer surgery. ANZ J Surg 2006;76:1088-95.

22. Lumachi F, Brandes AA, Burelli P, et al. Seroma prevention following axillary dissection in patients with breast cancer by using ultrasound scissors: a prospective clinical study. Eur J Surg Oncol 2004;30:526-30.

23. Cheng H, Clymer JW, Po-Han Chen B, et al. Prolonged operative duration is associated with complications: a systematic review and meta-analysis. J Surg Res 2018;229:134-44.
Cite this article as: Kim KE, Park H, Bae SH, Hwang BY, Kang T. Usefulness of using additional ultrasonic dissection device in breast cancer surgery: a retrospective cohort study. Gland Surg 2021;10(12):3181-3187. doi: 10.21037/gs-21-643 